\title{
Fraksisanasi dan distribusi keterikatan seng dalam sedimen Sendang Biru menggunakan metode BCR sonifikasi (The Bureau Community of Reference)
}

\author{
Miftachul huda putra pratama, Anugrah Ricky Wijaya*, Irma Kartika Kusumaningrum \\ Universitas Negeri Malang, Jl. Semarang No. 5 Malang, Jawa Timur, Indonesia \\ *Penulis korespondensi, Surel: anugrah.ricky.fmipa@um.ac.id
}

Paper received: Paper received: 01-02-2022; revised: 15-02-2022; accepted: 28-02-2022

\begin{abstract}
The density of anthropogenic activity in the port of blue fish leads to the contribution of heavy metals in sediments. The method of leaching is an important method to dissolve all zinc in the sediment precision and accuracy. Research on zinc levels in sediments has been widely practiced, but fractionation and distribution of zinc attachment in Blue Spring sediment using BCR Sonification. The results of the zinc analysis using BCR Sonification method gave precision value of $0.49 \%$, and accuracy of $91.20 \%$, the results showed that BCR method has high precision and accuracy value. The fractionation of zinc metal in the sediments shows that zinc is dominant in non-resistant (1) fractions comprising an ion exchange fraction, (2) carbonate bound fraction, (3) reduction fraction and (3) an oxidation fraction with a percentage of $10.16 \% ; 23.52 \% ; 21.25 \%$. Whereas in the fraction resistant or residual fraction the concentration of zinc in the sediment was $45.07 \%$. The distribution of zinc levels in sediments at nine locations in Sendang Biru ranged from $36.6 \mathrm{mg} / \mathrm{kg}-239,78 \mathrm{mg} / \mathrm{kg}$ indicating that the Blue Sendang sediment was partly contaminated from anthropogenic because the zinc levels had exceeded the ereference of $120 \mathrm{mg} / \mathrm{kg}$.
\end{abstract}

Keywords: fraction; distribution; Zn analysis; BCR sonification method

\begin{abstract}
Abstrak
Padatnya kegiatan antropogenik di pelabuhan ikan sendang biru menyebabkan adanya kontribusi seng dalam sedimen. Metode leaching merupakan metode yang penting untuk melarutkan semua seng dalam sedimen secara presisi dan akurasi. Penelitian kadar seng dalam sedimen telah banyak dilakukan, tetapi fraksinasi dan distribusi keterikatan seng dalam sedimen Sendang Biru menggunakan metode BCR Sonifikasi. Hasil penelitian analisis seng menggunakan metode BCR Sonifikasi memberikan nilai presisi sebesar 0,49\%, dan akurasi sebesar 91,20\%, hasil tersebut menunjukkan bahwa metode BCR memiliki nilai presisi dan akurasi yang tinggi. Fraksinasi logam seng dalam sedimen menunjukkan bahwa seng dominan pada fraksi non resisten yang terdiri dari fraksi (1) pertukaran ion, (2) fraksi terikat karbonat, (3) fraksi reduksi, dan (4) fraksi oksidasi dengan presentase sebesar $10,16 \% ; 23,52 \% ; 21,25 \%$, sedangkan pada fraksi resisten atau fraksi residu konsentrasi seng dalam sedimen adalah 45,07\%. Distribusi kadar seng dalam sedimen pada sembilan lokasi di Sendang Biru berkisar antara 36,6mg/kg - 239,78mg/kg. Hal ini menunjukkan bahwa sedimen Sendang Biru sebagian terkontaminasi dari antropogenik dengan kadar melebihi ambang batas yaitu sebesar $120 \mathrm{mg} / \mathrm{kg}$.
\end{abstract}

Kata kunci: fraksinasi; distribusi; analisis Zn; metode BCR sonifikasi

\section{Pendahuluan}

Sendang Biru merupakan salah satu pantai yang berada di wilayah kabupaten Malang yang memiliki sumberdaya perikanan yang besar. Hal ini dibuktikan dengan hasil tangkapan ikan yang ditampung di Pelabuhan Sendang Biru sebanyak 22.000 ton pertahun (Hermawan, 2006). Sedimen berasal dari bahasa Latin "sedimentum" yang artinya "pengendapan". Sedimen berasal dari peristiwa sedimentasi yang merupakan peristiwa pengendapan batuan yang telah diangkut oleh tenaga air atau angin melalui proses presipitasi, koagulasi, dan flokulasi. Pada lingkungan perairan, sedimen merupakan tempat akhir dari akumulasi senyawa logam. 
Berdasarkan penelitan yang dilakukan oleh Romlah (2016) nampak bahwa Zn merupakan salah satu logam berat yang terdapat dalam Sendang Biru. Tujuan penelitian ini adalah : (1) mengetahui presisi dan akurasi metode BCR sonifikasi untuk menentukan kadar tembaga dalam sedimen Sendang Biru, (2) mengetahui fraksi-fraksi tembaga yang terikat dalam sedimen Sendang Biru, dan (3) mengetahui distribusi tembaga dalam sedimen di wilayah Sendang Biru.

\section{Metode}

\subsection{Alat dan Bahan}

Alat-alat yang digunakan dalam penelitian ini adalah: grab sediment, seperangkat peralatan gelas untuk analisis kuantitatif, timbangan digital, oven, shaker, sentrifuge, stopwatch, dan Spektrofotometer Serapan Atom (SSA) Perkin Elmer A Analyst-700. Bahan dasar yang digunaka adalah sedimen yang diambil di Sendang Biru dan sedimen referen JSD-1 dari Japanese Society. Bahan kimia yang digunakan adalah larutan $\mathrm{CH} 3 \mathrm{COOH}$ glasial 95\%, serbuk NH2OH.HCl pro analysis, larutan $\mathrm{H} 2 \mathrm{O} 230 \%$, serbuk CH3COONH4 pro analysis, larutan HNO3 65\%, HCl 37\%, larutan HF 48\%, dan HNO3 1\%.

\subsection{Langkah Kerja}

Penentuan titik pengambilan sampel dilakukan secara random dengan mempertimbangkan tingkat kontaminasi logam yang diduga sangat tinggi sampai rendah. Pengambilan sampel dilakukan pada tahun 2016. Sampel sedimen yang diambil dengan menggunakan alat grab sediment pada kedalaman \pm 10 meter. Penentuan geografis titik pengambilan sampel menggunakan Global Positioning System (GPS), sehingga diperoleh 9 lokasi titik pengambilan sampel.

Sampel yang diperoleh dari Sendang Biru dimasukkan ke dalam wadah tertutup, kemudian dikeringkan di dalam oven pada suhu $\pm 60^{\circ} \mathrm{C}$, pengeringan ini dilakukan selama \pm 6 7 hari sampai sampel benar-benar kering hingga diperoleh berat konstan dan dapat digunakan dalam penelitian.

Sedimen dari Sendang Biru yang telah kering dan sedimen referen JSD-1 dianalisis kandungan tembaga. Analisis tembaga dalam sedimen menggunakan metode BCR sonifikasi dengan langkah sampel sedimen yang telah kering ditimbang sebanyak 0,5 g. Sampel dimasukkan ke dalam botol vial $50 \mathrm{~mL}$ dan ditambahkan dengan larutan $\mathrm{CH} 3 \mathrm{COOH}$ 0,11 M sebanyak 20 mL.Campuran kemudian di sonifikasi selama 15 menit. Setelah sonifikasi campuran dipisahkan menggunakan sentrifuge dengan kecepatan $3500 \mathrm{rpm}$. Hasil sentrifuge kemudian dipisahkan sentrat dan residu. Sentrat yang diperoleh dimasukan kedalam botol vial dan didapatkan fraksi pertama (fraksi penukar ion), sedangkan residu yang diperoleh dilanjutkan pada tahap selanjutnya.

Residu yang diperoleh dari fraksi pertama ditambahkan larutan NH2OH-HCL 0,5 M sebanyak $20 \mathrm{~mL}$ yang berfungsi sebagai agen reduktor. Campuran kemudian disonifikasi selama 15 menit, setelah sonifikasi campuran dipisahkan menggunakan sentrifuge dengan kecepatan $3500 \mathrm{rpm}$. Hasil sentrifuge kemudian dipisahkan sentrat dan residunya. Sentrat yang diperoleh dimasukkan kedalam botol vial dan didapatkan fraksi kedua (fraksi terikat karbonat), sedangkan residu yang diperoleh dilanjutkan pada tahap selanjutnya. 
Residu yang diperoleh dari fraksi kedua ditambahkan larutan $\mathrm{H} 202$ 30\% sebanyak $5 \mathrm{~mL}$ yang berfungsi sebagai agen oksidator, dipanaskan kedalam penangas air pada suhu $85^{\circ} \mathrm{C}$ selama 1 jam dan dilakukan sebanyak dua kali penambahan. Setelah pemanasan larutan ditunggu dingin dan ditambahkan larutan CH3COONH4 1 M pada pH 2 kemudian disonifikasi selama 15 menit setelah sonifikasi campuran dipisahkan menggunakan sentrifuge dengan kecepatan $3500 \mathrm{rpm}$. Hasil sentrifugasi dipisahkan sentrat dan residunya. Sentrat yang diperoleh dimasukkan kedalam botol vial dan didapatkan fraksi ketiga (fraksi oksidasi).

Residu yang diperoleh dari fraksi ketiga ditambahkan larutan HF dan HNO3 Pekat selanjutnya dipanaskan hingga suhu $110^{\circ} \mathrm{C}$ sampai kering dan dilanjutkan dengan penambahan HNO3 $1 \% 2 \mathrm{ml}$ sebanyak lima kali pengulangan hingga semua residu larut. Larutan yang diperoleh dianalisis menggunakan spektrofotometer serapan atom untuk mengetahui konsentrasi $\mathrm{Cu}$ pada fraksi residual (diadopsi dari Arain et al., 2008\&Wijaya et al., 2016).

\section{Hasil dan Pembahasan}

\subsection{Efektivitas Metode BCR Sonifikasi dalam Mendekomposisi Logam Tembaga dalam Sedimen Sendang Biru}

Suatu metode yang digunakan di laboratorium harus diuji keefektifannya, pengujian ini meliputi presisi dan akurasi, untuk menghasilkan data yang baik dan benar sesuai peruntukannya (Riyanto, 2014). Pada uji presisi ditunjukkan dengan Relatif Standart Deviation $\%$ RSD, semakin kecil \% RSD maka semakin tinggi tingkat ketelitiannya (Riyanto, 2014). Pada penelitian ini diperoleh \% RSD sebesar 0,05\% sehingga metode BCR sonifikasi ini memiliki tingkat ketelitian yang tinggi untuk mendekomposisi logam tembaga dalam sedimen Sendang Biru.

Uji akurasi metode BCR sonifikasi untuk leaching logam tembaga dalam sedimen digunakan sedimen referan JSD-1. Penggunaan sedimen referen ini dikarenakan sedimen referen merupakan bahan standar yang telah memiliki nilai terukur sehingga dapat dijadikan sebagai nilai acuan untuk nilai sebenarnya. Menurut (Riyanto, 2014) akurasi ditentukan dengan \% recovery, berdasarkan hasil analisis tembaga dalam sedimen sendang biru diperoleh hasil \% recovery sebasar 90,36\%. Menurut Horwitz (2002), suatu metode yang akurat memiliki persentase perolehan kembali antara $85-110 \%$ oleh karena itu metode BCR sonifikasi dapat dikatakan memiliki akurasi yang tinggi.

\subsection{Fraksinasi Keterikatan Logam Seng dalam Sedimen Sendang Biru}

Fraksinasi keterikatan logam dalam sedimen mengindikasikan mekanisme mobilisasi keterikatan logam dalam sedimen melalui hasil fraksi yang diperoleh. Fraksi-fraksi dalam sedimen diklasifikasikan ke dalam dua tipe, yaitu fraksi resisten dan non resisten. Fraksi resisten merupakan fraksi keterikatan logam dalam sedimen yang tidak dapat diserap oleh organisme, sedangkan fraksi non resistan merupakan fraksi keterikatan logam dalam sedimen yang mampu diserap dan diakumulasi oleh organisme atau dapat dikatakan bahwa fraksi non resisten bertanggung jawab terhadap ketersediaan logam secara biologi (bioavailability) dalam sedimen bagi organisme. Untuk fraksinasi menggunakan metode BCR sonifikasi memiliki empat fraksi, yaitu: (1) Fraksi penukaran ion dan terikat karbonat, (2) Fraksi Reduksi, (3) Fraksi Oksidasi, (4) Fraksi Residu. Dimana pada fraksi 1-3 termasuk fraksi non resisten dan fraksi 4 merupakan fraksi resisten yang keberadaan logamnya tidak larut keperairan. 
Keberadaan tembaga dalam sedimen di sembilan lokasi titik pengambilan sampel lebih banyak ditemukan dalam bentuk non resistan dengan rata-rata persentase konsentrasi sebesar $645,07 \%$, sedangkan untuk fraksi non resistan sebesar 54,93\%. Perbedaan hasil yang diperoleh pada setiap fraksi dipengaruhi oleh kontaminasi antropogenik. Pada fraksi non resistan sumber pencemar logam berasal dari aktivitas manusia (anthropogenic source), sedangkan pada fraksi resistan berasal dari mineral alami (natural source) (Wijaya et al., 2016). Tingginya presentase tembaga pada fraksi non resistan mengindikasikan bahwa sedimen relatif terkontaminasi dan membahayakan bagi sistem ekologi dan biologis di perairan.

\subsection{Distribusi Keterikatan Logam Seng dalam Sedimen Sendang Biru}

Pada umumnya konsentrasi logam tertinggi terakumulasi pada partikel sedimen yang lebih kecil, sedangkan konsentrasi logam terendah terakumulasi pada partikel yang berukuran lebih besar. Konsentrasi seng tertinggi dalam sedimen yang berupa lumpur $>$ tanah liat $>$ pasir berlumpur>pasir murni. dari hasil analisis menunjukkan bahwa pada titik pertama memiliki konsentrasi yaitu $221,79 \mathrm{mg} / \mathrm{Kg}$, nilai kandungan logam seng pada lokasi pertama ini merupakan daerah paling tinggi, karena pada lokasi ini merupakan daerah yang berdeakatan dengan pelabuhan ikan yang memungkinkan pembuangan limbah masuk kedalam perairan. Berdasarkan hasil yang diperoleh menunjukkan bahwa konsentrasi tembaga dalam sedimen pada lokasi $9<2<3<8<7<4<5<1<6$.

\section{Simpulan}

\subsection{Kesimpulan} berikut:

Berdasarkan penelitian yang telah dilakukan dapat diperoleh kesimpulan sebagai

4.1.1. Presisi metode BCR (The Bereau Community of Reference) dalam menganalisis Zn dalam sedimen Sendang Biru menghasilkan nilai \%RSD sebesar 0,49\% sedangkan akurasinya nilai \%Recovery sebesar 91,20\%. Dengan demikian metode BCR sonifikasi memiliki presisi dan akurasi yang tinggi.

4.1.2. Fraksinasi keterikatan seng dalam sedimen Sendang Biru di 9 lokasi titik pengambilan sampel dominan pada fraksi non resisten, diperoleh rata-rata persentase yaitu 10,16\%; 23,52\%; 21,25\%; dan 45,07\%, sehingga kontaminan logam seng dalam sedimen Sendang Biru berasal dari aktifitas antropogenik.

4.1.3. Distribusi kandungan seng dalam sedimen Sendang Biru di 9 lokasi pengambilan sampel menunjukkan bahwa konsentrasi tertinggi dan melebihi ambang batas berada pada lokasi ke 6, 1, 4 dan 5 sedangkan pada lokasi ke 2, 3, 7, 8, dan 9 masih dibawah ambang batas. Hal ini menunjukkan bahwa logam seng dalam sedimen Sendang Biru secara umum tidak berbahaya bagi organisme perairan, namun tetap harus ada penanganan lebih lanjut pada titik-titik yang terkontaminasi khususnya pada lokasi 1, 4 dan 5.

\subsection{Saran}

Berdasarkan hasil penelitian dapat dikemukakan saran untuk: 
4.2.1. Dilakukan penelitian menggunakan metode BCR Sonifikasi (The Bereau Community of Reference) untuk analisis kadar logam yang lain, selain tembaga di dalam sedimen Sendang Biru agar dapat ditentukan kualitas dari sedimen.

4.2.2. Dilakukan ayakan atau mesh pada sampel sedimen sebelum dilakukan analisis untuk meningkatkan homogenitas dengan pelarut.

\section{Ucapan Terima Kasih}

Penelitian ini didanai oleh kemenristek dikti, skema fundamental tahun 2015-2016, DIPA Nomor 042.06-0/2016 tanggal 7 Desember 2015 dengan judul “ Kajian Metode Partial dan Total Didestion Pada Fraksi Sedimen Menggunakan AAS (Atomic Absorption Spectroscopy) dan Aplikasinya Pada Sedimen Pelabuhan Ikan Internasional Sendang Biru" atas nama Dr. Sc. Anugrah Ricky Wijaya, S.Si., M.Sc.

\section{Daftar Rujukan}

Arain, M. B., Kazi, T. G., Jamali, M. K., Jalbani, N., Afridi, H. I., \& Baig, J. A. (2008). Speciation of heavy metals in sediment by conventional, ultrasound and microwave assisted single extraction methods: a comparison with modified sequential extraction procedure. Journal of hazardous materials, 154(1-3), 998-1006.

Horwitz, W. (2002). AOAC guidelines for single laboratory validation of chemical methods for dietary supplements and botanicals. Gaithersburg, MD, USA: AOAC International, 12-9.

Bernhard, M., Brinkman, F. E., \& Sadler, P. J. (1998). The importance of chemical speciation in environmental process. Paper in Dahlem Konferenzen, Berlin, 2-7 September

Burton, E. D., Phillips, I. R., \& Hawker, D. W. (2006). Factors controlling the geochemical partitioning of trace metals in estuarine sediments. Soil and Sediment Contamination: An International Journal, 15(3), 253276.

Christian, D.G. (1994). Analitical chemistry. New York: John Wiley and Sons Inc.

Davidson, C. M., Thomas, R. P., McVey, S. E., Perala, R., Littlejohn, D., \& Ure, A. M. (1994). Evaluation of a sequential extraction procedure for the speciation of heavy metals in sediments. Analytica Chimica Acta, 291(3), 277-286.

El-Mansy, N. (2013). Solid-liquid extraction. Chemical Engineering Department, Cairo University.

Filgueiras, A. V., Lavilla, I., \& Bendicho, C. (2002). Chemical sequential extraction for metal partitioning in environmental solid samples. Journal of Environmental Monitoring, 4(6), 823-857.

Kennedy, V. H., Sanchez, A. L., Oughton, D. H., \& Rowland, A. P. (1997). Use of single and sequential chemical extractants to assess radionuclide and heavy metal availability from soils for root uptake. Analyst, 122(8), 89R-100R.

Mulyaningsih, T. R., AlFian, A., \& Sutisna, S. (2012). Distribusi Logam Berat Dalam Sedimen Daerah Aliran Sungai Ciujung Banten. Jurnal Teknologi Reaktor Nuklir Tri Dasa Mega, 14(3), 157-169.

Palar, H. (2004). Pencemaran dan Toksisitas Logam Berat. Jakarta: Rineka Cipta.

de Andrade Passos, E., Alves, J. C., dos Santos, I. S., Jose do Patrocínio, H. A., Garcia, C. A. B., \& Costa, A. C. S. (2010). Assessment of trace metals contamination in estuarine sediments using a sequential extraction technique and principal component analysis. Microchemical Journal, 96(1), 50-57.

Pueyo, M., Rauret, G., Lück, D., Yli-Halla, M., Muntau, H., Quevauviller, P., \& López-Sánchez, J. F. (2001). Certification of the extractable contents of $\mathrm{Cd}, \mathrm{Cr}, \mathrm{Cu}, \mathrm{Ni}, \mathrm{Pb}$ and $\mathrm{Zn}$ in a freshwater sediment following a collaboratively tested and optimised three-step sequential extraction procedure.Journal of Environmental Monitoring, 3(2), 243-250. 